\title{
Metal-Based Nanoparticles and the Immune System: Activation, Inflammation, and Potential Applications
}

\author{
Yueh-Hsia Luo, ${ }^{1}$ Louis W. Chang, ${ }^{2}$ and Pinpin Lin $^{1,2}$ \\ ${ }^{1}$ Division of Environmental Health and Occupational Medicine, National Health Research Institutes, \\ 35 Keyan Road, Zhunan 35053, Miaoli County, Taiwan \\ ${ }^{2}$ National Environmental Health Research Center, National Health Research Institutes, 35 Keyan Road, \\ Zhunan 35053, Miaoli County, Taiwan \\ Correspondence should be addressed to Pinpin Lin; pplin@nhri.org.tw
}

Received 16 December 2014; Accepted 19 February 2015

Academic Editor: Il Je Yu

Copyright (C) 2015 Yueh-Hsia Luo et al. This is an open access article distributed under the Creative Commons Attribution License, which permits unrestricted use, distribution, and reproduction in any medium, provided the original work is properly cited.

Nanomaterials, including metal-based nanoparticles, are used for various biological and medical applications. However, metals affect immune functions in many animal species including humans. Different physical and chemical properties induce different cellular responses, such as cellular uptake and intracellular biodistribution, leading to the different immune responses. The goals of this review are to summarize and discuss the innate and adaptive immune responses triggered by metal-based nanoparticles in a variety of immune system models.

\section{Introduction}

Nanotechnology is one of the most exciting industrial innovations of the 21st century. Nanomaterials are used in various industrial applications and products, including sporting goods, tires, sunscreens, cosmetics, electronics, and fuel additives as well for a variety of medical purposes such as diagnostic imaging and drug delivery. Many nanomaterials are metal-based nanoparticles, such as nanosilver, nanometallic oxides (zinc oxide, titanium dioxide, iron oxide, and quantum dots), and are applied for many uses [1]. For example, zinc oxide $(\mathrm{ZnO})$ and titanium dioxide $\left(\mathrm{TiO}_{2}\right)$ are used in sunscreens and cosmetic products $[2,3]$, and nanosilver is used in detergents, antibacterial agents, paints, printer inks, and textiles [4-9].

Nanoparticles frequently have remarkably different physicochemical properties than their conventional bulk materials. These properties can be a "double-edged sword," providing positive advantages for usefulness and negative impacts on health upon exposure. Toxicity due to some metal-based nanoparticles such as silver, gold, and copper increased with decreasing nanoparticle size [10]. Other physicochemical properties such as elemental composition, charge, shape, crystallinity, surface area, solubility, and surface derivatives also influence the toxic potential of the compounds [11-15]. Therefore, metal-based nanoparticle should not be considered a homogeneous population with simple toxic attributes because they act independently to mediate diverse biological reactions.

Many investigators have explored the properties and toxicities of various metal-based nanoparticles. The toxicities of various metal-based nanoparticles, both in vitro and in vivo, were recently reviewed and summarized by Schrand et al. (Table 1) [10].

The engineering of nanoparticles for application in the immune system is now an exciting, emerging field. Although certain nanomaterials are immunotoxic or immunomodulatory, a concise overview of the interactions between nanoparticles and the immune system would be valuable and indispensable to students and researchers alike. The focus of this review is to outline the interactions of innate and adaptive immune systems with metal-based nanoparticles (Figure 1). We discuss the role of toll-like receptors interaction with nanoparticles and their potential implications. Different effects of nanoparticles on innate immune cells (macrophages, dendritic cells, neutrophils, mast cells, and 


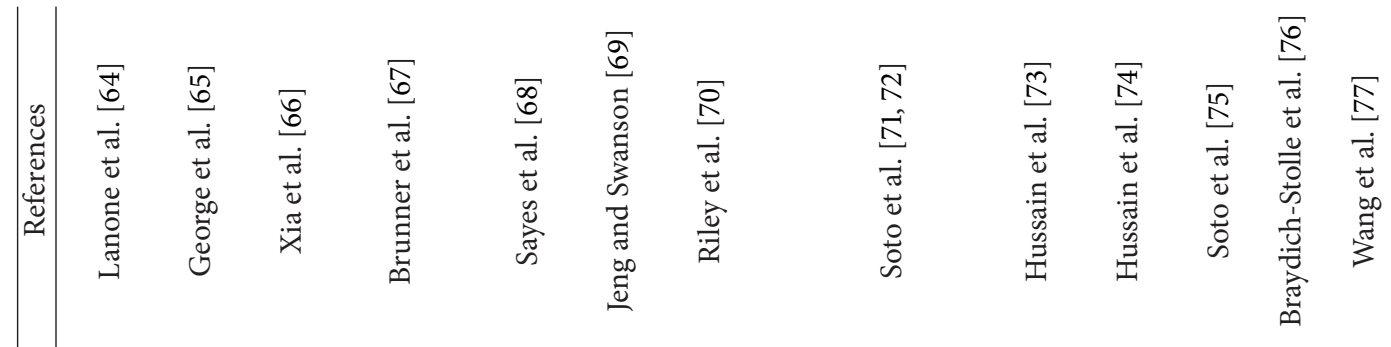

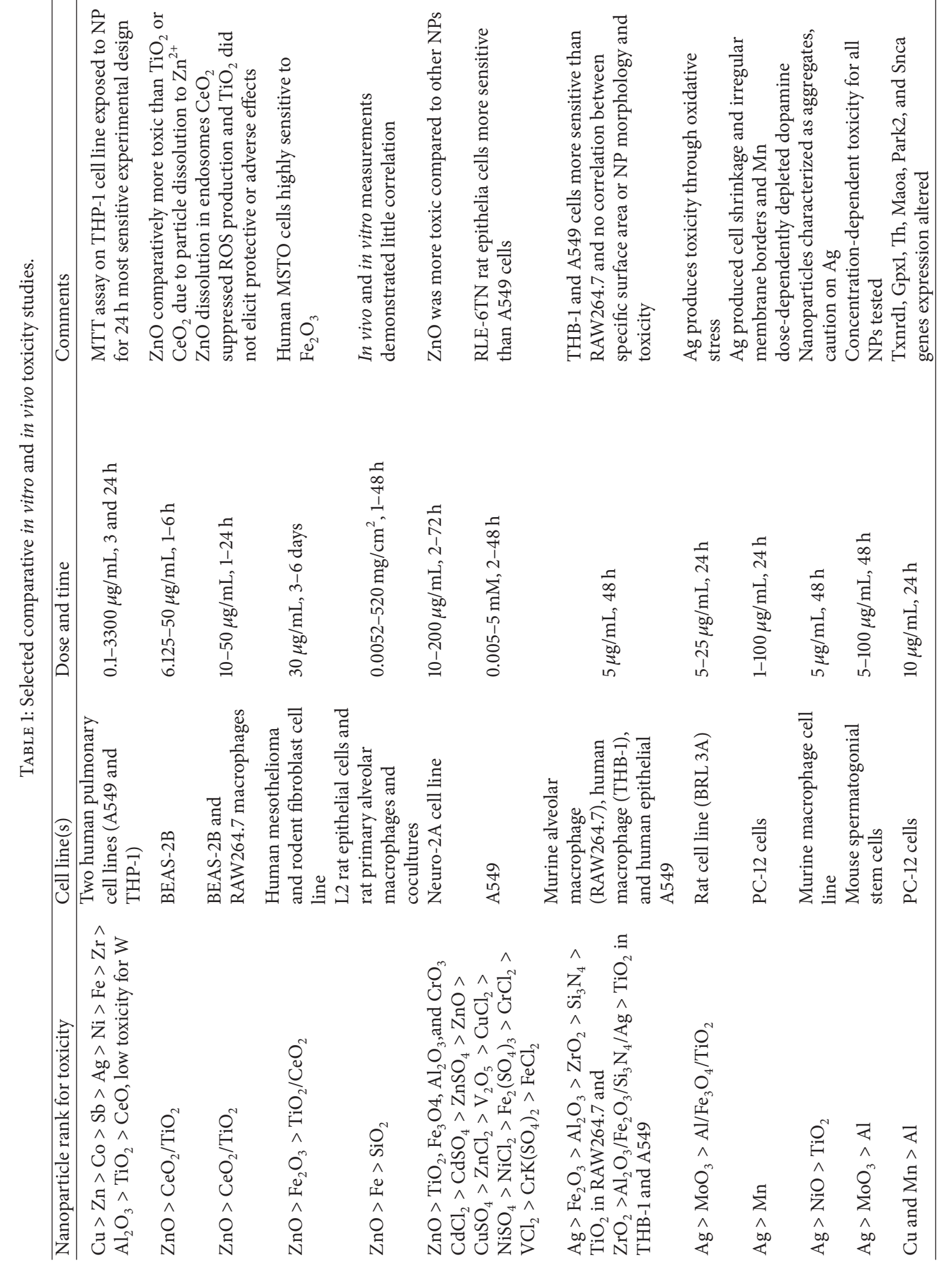

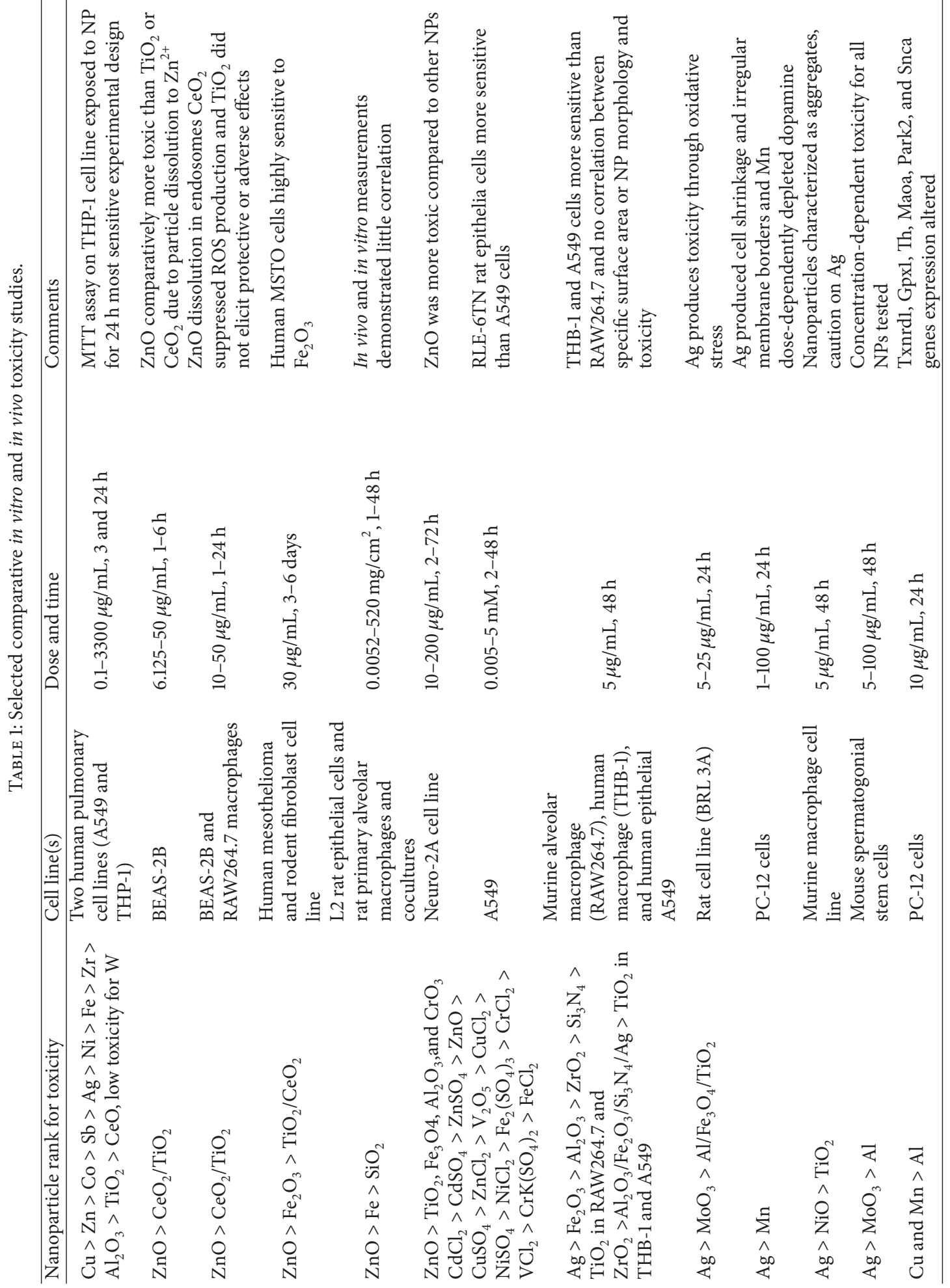
政

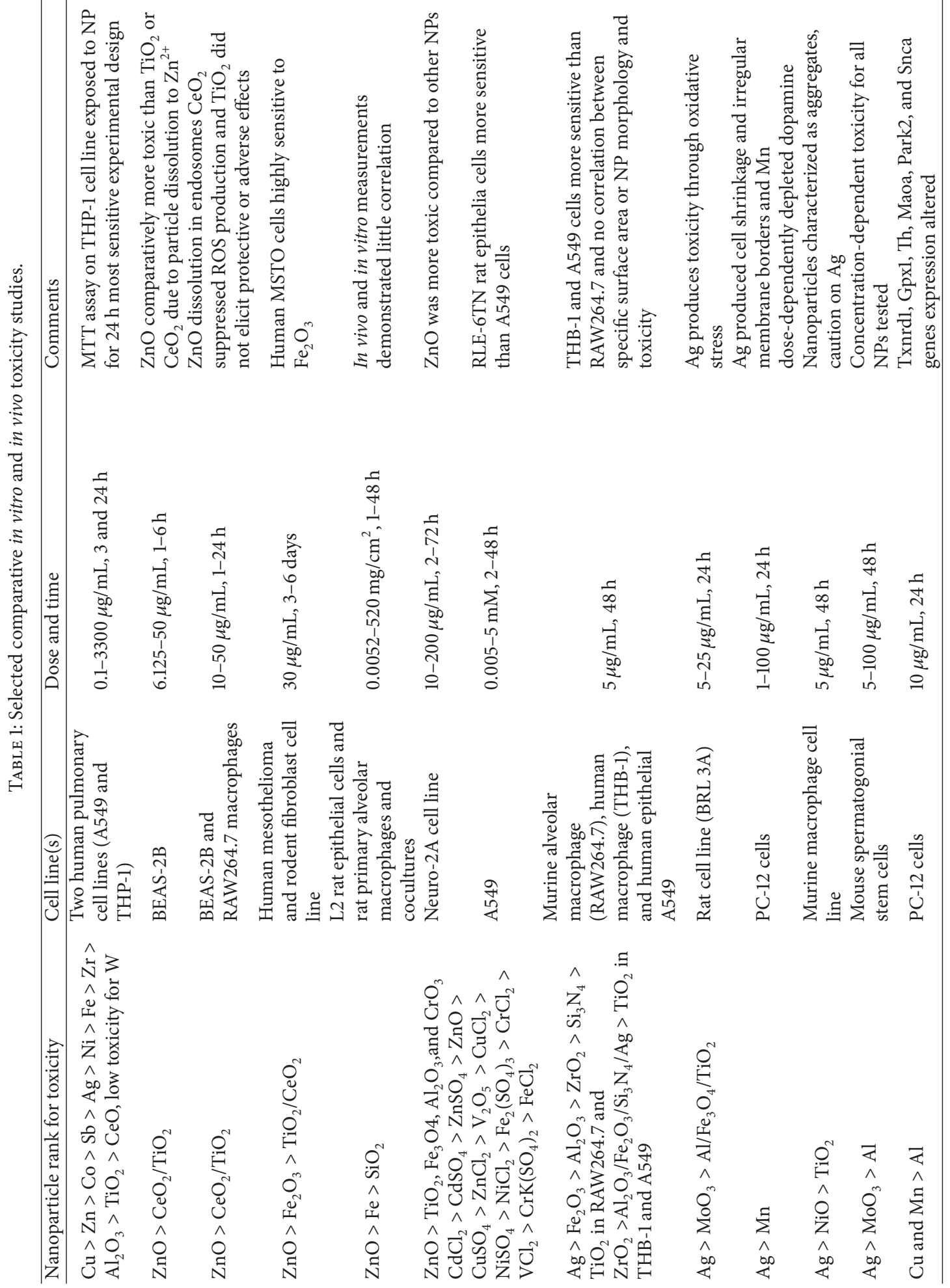




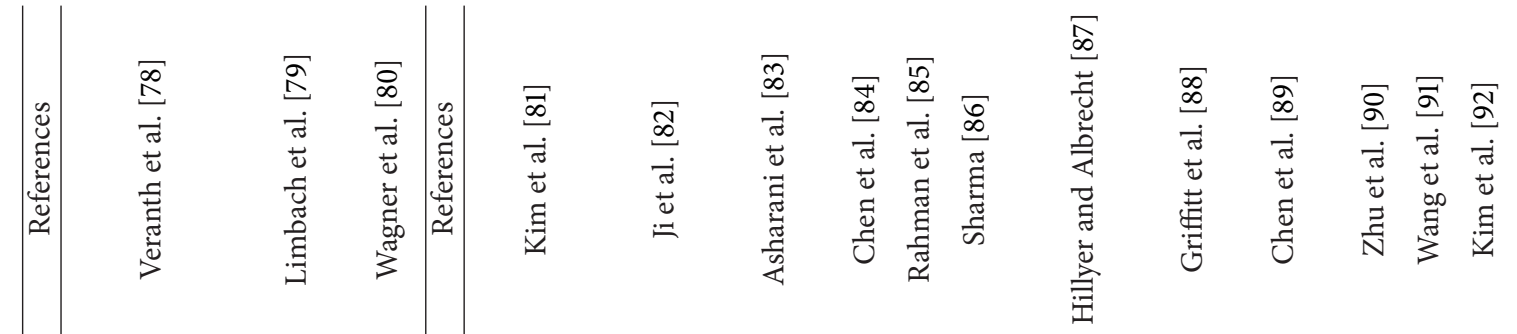

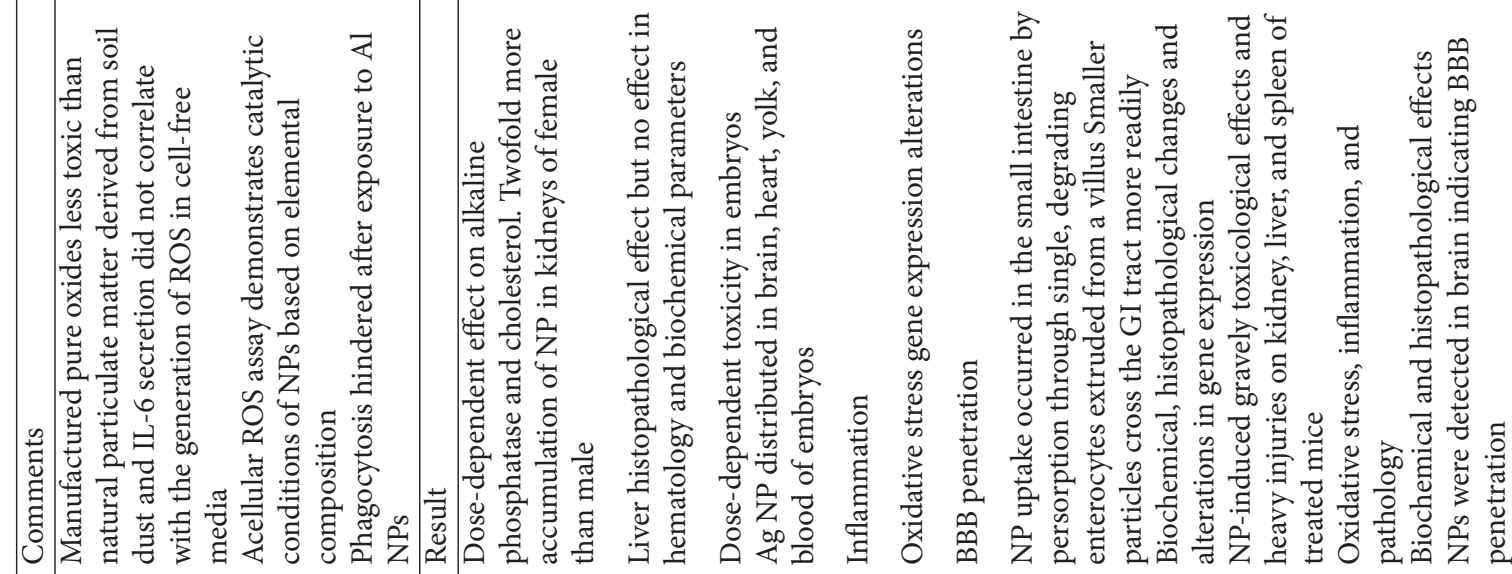

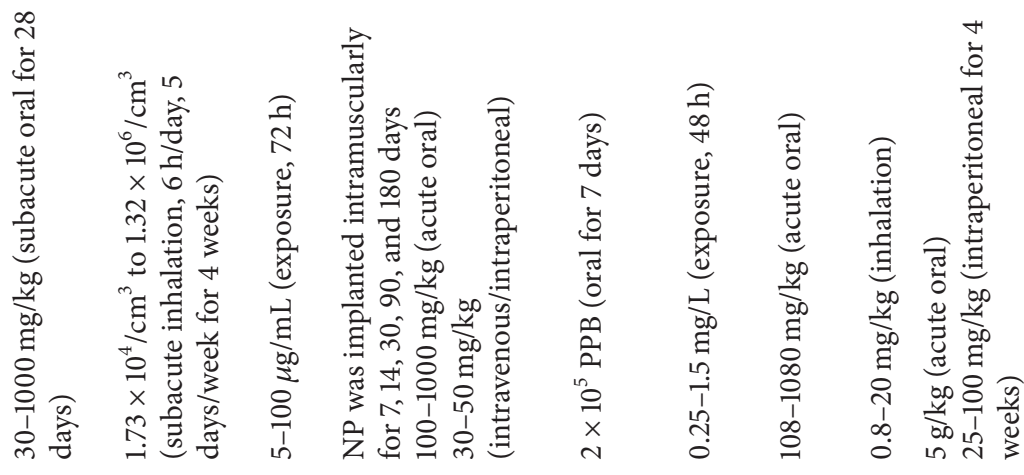

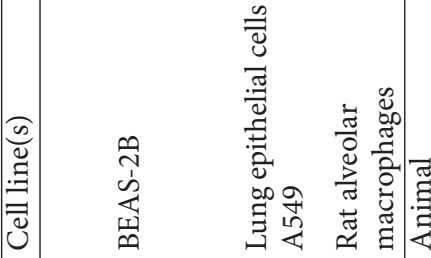

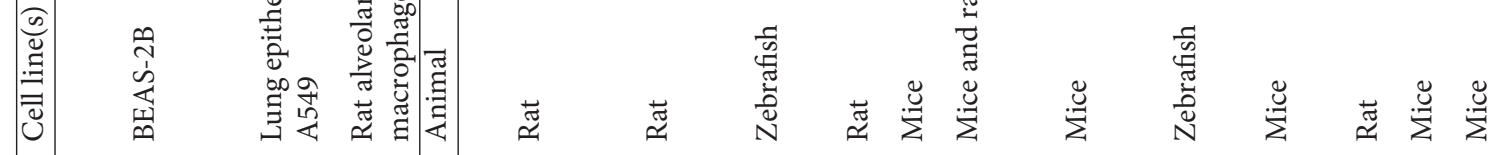

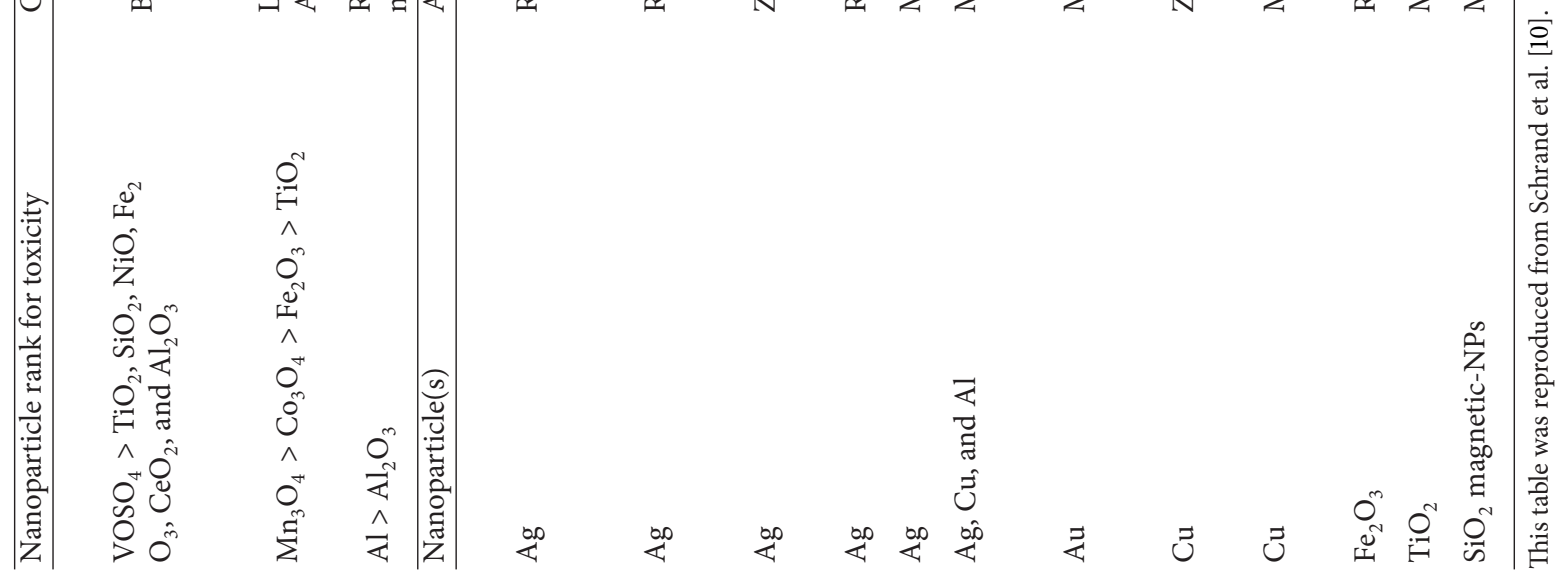




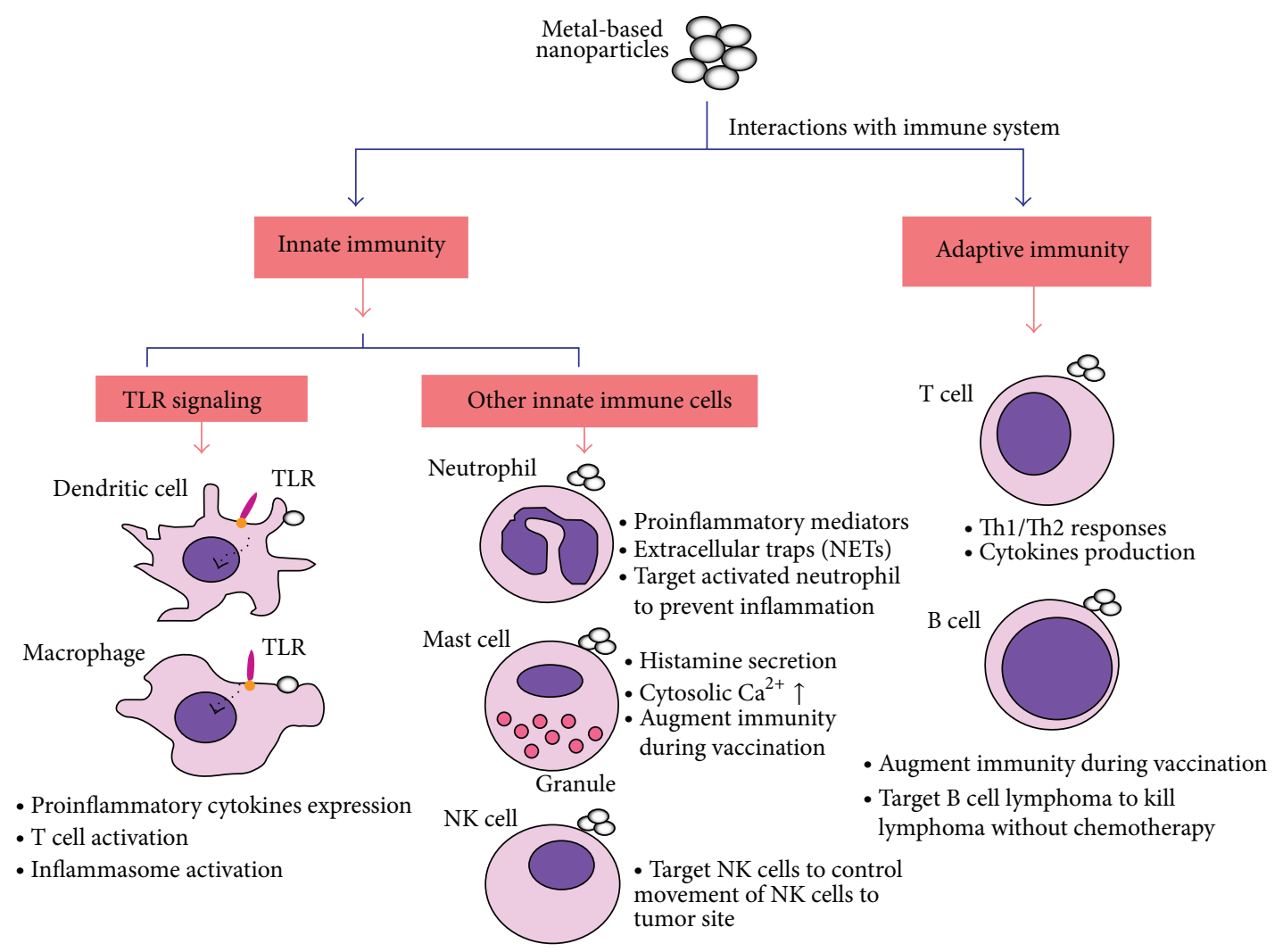

FIGURE 1: Metal-based nanoparticles interaction with immune system.

natural killer cell) and adaptive immune cells ( $\mathrm{T}$ cells and $B$ cells) are reviewed. This information will enhance the understanding for immunological effects of nanomaterials and help to develop safe metal-based nanoproducts.

\section{Nanoparticles and Immune System}

The immune system can defend against foreign antigens, which has been divided into two general types of immunity: innate immunity and adaptive immunity. Innate immunity is the nonspecific and first line of the body's defense system, which relies on pattern recognition receptors (PRPs) to recognize broad and conserved molecular patterns found on pathogens (pathogen-associated molecular patterns, PAMPs) [16]. Therefore, the innate immune system plays an essential role in the early recognition and subsequent proinflammatory response. The adaptive immune system is antigen specific and reacts only with the organism that induced the response. Innate and adaptive immunity can be thought of as two equally important aspects of the immune system.

Most nanoparticles are recognized as foreign materials and eliminated by the immune system. However, in the immune system, if the foreign materials are not recognized as a threat, they are ignored or tolerated. Undesirable overwhelming activation of immune responses may lead to harmful consequences. Therefore, the response of the immune system to the nanoparticles must be considered when developing a nanomaterial for in vivo application. For example, avoiding immune system detection is crucial if a nanomaterial is to be used for gene or drug delivery [17]. In contrast with avoiding immune system of nanoparticle drug delivery, nanoparticles also can play importing role in vaccine immunization via antigen delivery and adjuvanticity. Another viewpoint is that nanoparticles targeting immune cell (e.g., macrophages or dendritic cells) can manipulate or control immunological diseases such as infectious disease or tumor therapy. For example, nanomaterial might be designed to modify effective immune responses of tumor microenvironment via accompanied with anti-inflammatory drug or specific cytokines.

Three immune related consequences must be considered when a nanomaterial is engineered for application in vivo. The first is immune-mediated destruction or rejection, which could initiate a defensive immune reaction resulting in the elimination of the nanomaterials. Second is immunotoxicity, which could damage the immune system and cause pathological changes. The third is immunocompatibility, which does not interfere with the immune response [18]. Nanoparticle properties such as size, charge, hydrophobicity, hydrophilicity, and the steric effects of nanoparticle coatings direct nanoparticle compatibility with the immune system [17, 19, 20]. For example, nanoparticles that are designed by encapsulated PEG or other types of polymers provide a hydrophilic environment and shield them from immune recognition [21]. However, some reports showed that the immune system can produce PEG-specific antibodies after administration of PEG-coated liposomes [22, 23]. The 
researches focus on how and whether nanoparticles triggered antibodies production is limited and we need further studies to answer these inconclusive questions.

2.1. Nanoparticles and Innate Immunity. Innate immune system consists of different cells and proteins that are nonspecific and first line of defense system. The main components of the innate immune system are including physical epithelial barriers, phagocytic cells (monocyte/macrophages, dendritic cells, and polymorphonuclear leukocytes), phagocytic leukocytes, basophils, mast cells, eosinophils, natural killer (NK) cell, and circulating plasma proteins.

In recent decades, many studies have rapid progress in toll-like receptor of innate system, which induce expression genes of involved inflammation. Moreover, toll-like receptors activate both innate and adaptive immune system and play an important role in antiviral and anti-immunity [24]. In this review, we will first discuss the toll-like receptor signaling mechanisms triggered by metal-based nanoparticles and then describe the effects of nanoparticles on other innate immune cells.

2.2. The Role of Toll-Like Receptor Signaling in Innate Immune System. The innate immune system, also known as nonspecific immune system and first line of defense, relies on recognition of PAMPs through a limited number of germ line-encoded pattern recognition receptors, belonging to the family of toll-like receptors (TLRs) [25]. The Toll gene was originally discovered in Drosophila, responsible for dorsoventricular polarization during embryonic development and antifungal and antibacterial properties of the adult fly [26]. TLR1, TLR2, TLR4, TLR5, TLR6, and TLR10 are present on the cell surface whereas TLR3, TLR7, TLR8, TLR9, TLR12, and TLR13 are localized into intracellular vesicles such as endosomes, lysosomes, and ER. TLR1/TLR2 sense bacterial tri-acylated lipopeptides. TLR2/TLR6 recognize diacetylated lipopeptides and bacterial lipoteichoic acid or peptidoglycans and mycobacterial cell wall components. TLR3 binds to viral double stranded RNA; while TLR4 responds to LPS, TLR5 senses flagellin. TLR7 and TLR8 respond to the single stranded RNA from viruses, while TLR9 binds to DNA-containing unmethylated $\mathrm{CpG}$ motifs which are commonly found in bacterial DNA. TLR12 recognizes profilin, while TLR13 senses bacterial 23S ribosomal RNA (rRNA) [16]. The activations of TLR signalings can not only induce cytokines production but also increase macrophages phagocytosis and natural killer (NK) cells cytolytic activity. Most importantly, TLR signaling activations also can enhance antigen presentation via upregulating the expression of major histocompatibility complex (MHC) and costimulatory molecules (CD80 and CD86) on dendritic cells leading to adaptive immunity activations. Thus, the TLR agonists were believed as powerful vaccine adjuvants, allergy, infection, and antitumor therapeutics in preclinical studies [24]. The TLR antagonists also have therapeutic values in clinical trial to treat septic shock and autoimmune [27]. For example, TLR agonists or nanoparticles that enhanced TLR signaling pathways would be powerful adjuvants $[28,29]$. In contrast,
TLR antagonists or inhibitors that reduced the inflammatory response would have beneficial therapeutic effects in autoimmune diseases and sepsis [30]. These potential applications may open up innovative directions for the design of nanoparticle conjugates to meet different requirements.

\subsection{Effects of Nanoparticles on TLR Signaling of Innate Immu-} nity. TLRs are classified as type I transmembrane receptors containing an $\mathrm{N}$-terminal leucine-rich repeat domain (transmembrane region) and a C-terminal cytoplasmic domain. Upon recognition of a PAMP, TLRs recruit a specific set of adaptor molecules that contain the TIR domain, such as MyD88 and TRIF, and initiate downstream signaling events that lead to the secretion of inflammatory cytokines, type I IFN, and chemokines [31]. The TLR signaling cascade results in the activation of transcription factors, nuclear factor $\kappa$ light chain enhancer of activated B cells (NF- $\kappa \mathrm{B})$, interferon-regulatory factors (IRFs), and mitogen-activated protein kinase; these factors affect the transcription of genes involved in inflammatory and immune responses [32, 33].

Schmidt et al. first reported that $\mathrm{Ni}^{2+}$ as an inorganic activator was acting directly through TLR binding to trigger inflammation responses [34]. This interesting finding also makes us think of whether the other chemicals components such as metal-based nanoparticles were also involved in TLR signaling inflammation. Recently, several studies have demonstrated the effects of nanoparticles on innate immunity via TLR signaling pathways [35]. Several nanoparticles (e.g., $\mathrm{TiO}_{2}, \mathrm{ZnO}$, zirconium dioxide $\left(\mathrm{ZrO}_{2}\right)$, and silver $)$ modulated immune responses via TLRs. $\mathrm{TiO}_{2}$ and $\mathrm{ZrO}_{2}$ nanoparticles increased TLRT and TLR10 mRNA levels in human macrophage U-937 cells and TLR2 and TLR4 mRNA levels in the mouse liver cells $[36,37]$. N-(2-Mercaptopropionyl) glycine (tiopronin) capped-silver nanoparticles enhanced the TLR3 ligand and TLR9 ligand-induced IL-6 secretion in mouse macrophage Raw264.7 cells [38]. ZnO nanoparticles induced MyD88-dependent proinflammatory cytokines via a TLR signal pathway [39]. Quantum dot 705 activated MyD88-dependent TLRs at the surface or inside of cells, which is a fundamental mechanism for nanoparticle-induced inflammatory responses [40]. TLRs may have important roles not only for different NPs uptake but also for their cellular response [41]. Moreover, the mechanisms of interaction between NPs and TLR are still unclear. There are two possibilities to explain how NPs interact with TLRs. One is that the smaller NPs may just like LPS have cooperated with some small molecules such as the LPS binding protein and then the complex activates further TLRs signaling pathways. The other is that the larger size of NPs may directly associate with TLRs [41]. However, these hypotheses need more studies to confirm.

Proinflammatory cytokines can be induced by TLR signaling pathways. Many cytokines, such as interleukin- (IL-) 1, IL-6, and tumor necrosis factor- (TNF-) $\alpha$, can activate inflammatory cells, increase vascular permeability, and cause swelling and redness during acute inflammatory responses [42]. IL-1 and IL-6 are important mediators of fever [43]. TNF- $\alpha$ activates endothelial cells leading to hypotension. 
IL-8 is a chemokine that activates neutrophils or other granulocytes and recruits them to the site of inflammation [44]. Interferon- (IFN-) $\gamma$ plays an important role in the inflammatory process, recruiting macrophages to the site where antigen is present [42]. Many studies have reported that NPs can trigger cytokines production which associated with inflammatory responses. The levels of proinflammatory cytokines are measured as biomarkers of nanoparticle immunomodulatory effects and immune-mediated toxicity [42]. $\mathrm{TiO}_{2}$ nanoparticles, nanodiamond, and nanoplatinum also are reported to trigger proinflammatory cytokine production, dendritic cell maturation, and naïve $\mathrm{T}$ cell activation and proliferation $[45,46]$. Hanley et al. also reported that $\mathrm{ZnO}$ nanoparticles increased the expression of IFN- $\gamma$, TNF$\alpha$, and IL-12 in primary human immune cells [47]. Gold nanoparticles (10 $\mathrm{nm}$ and $50 \mathrm{~nm}$ in size) induced IL-1 $\beta$, IL-6, and TNF- $\alpha$ in rat liver cells after 1 day of acute treatment and then subsided by day 5 of subchronic treatment. The $50 \mathrm{~nm}$ gold nanoparticles produced more severe inflammation than the $10 \mathrm{~nm}$ gold nanoparticles [48]. However, limited studies demonstrated whether or which TLR is involved in the NPs induced proinflammatory cytokines production.

Another interesting field is inflammasomes which are multiprotein complexes leading to caspase- 1 activation, further causing pro-IL-1 $\beta$ and pro-IL-18 maturations and secretions. The IL- $1 \beta$ synthesis and secretion are tightly regulated by TLR signaling and inflammasome activation. A first signal, such as toll-like receptor activation, triggers synthesis of proIL- $1 \beta$ by transcriptional induction, whereas a second stimulus leads to inflammasome oligomerization, caspase-1 autoactivation, and caspase-1-dependent cleavage and release of the biologically active, mature IL-1 $\beta$ [49]. The second signal can be triggered by an ever-expanding group of chemically and biologically unrelated danger-associated molecular patterns (DAMPs) or pathogen-associated molecular patterns (PAMPs) [50]. The study of nanoparticles that induce IL$1 \beta$ via inflammasome signaling pathways mechanism is an emerging theme $[51,52]$.

Some engineered nanoparticles can also activate inflammasome signaling pathways [49, 53, 54]. Among various inflammasomes, nucleotide-binding oligomerization domain- (NOD-) like receptor protein 3 (NLRP3) activation is linked to exposure to various nanoparticles $[54,55]$. $\mathrm{TiO}_{2}$ and $\mathrm{SiO}_{2}$ nanoparticles activate the NLRP3 inflammasome and IL-1 $\beta$ release in LPS-primed murine bone marrow-derived macrophages and human macrophage cell lines THP-1 [49, 56]. Peeters et al. [55] recently reported that crystalline silica $\left(\mathrm{SiO}_{2}\right)$ activated NLRP3 inflammasomes in human lung epithelial cells BEAS-2B and primary human bronchial epithelial cells, which prolonged the inflammatory signal and affected fibroblast proliferation. Silver nanoparticles induced inflammasome formation and triggered IL-1 $\beta$ release and subsequent caspase- 1 activation [53]. Inflammasome-activation-associated IL- $1 \beta$ production by dendritic cells in response to particle treatment was size-dependent and maximal at particle diameters between 400 and $1000 \mathrm{~nm}$ [57]. Yazdi et al. reported that nano$\mathrm{TiO}_{2}$ and nano-SiO 2 , but not nano-ZnO, activate the NLRP3 inflammasome, leading to IL- $1 \beta$ release, and in addition induce the regulated release of IL- $1 \alpha$. Unlike other particulate NLRP3 agonists, nano- $\mathrm{TiO}_{2}$-dependent NLRP3 activity does not require cytoskeleton-dependent phagocytosis and induces IL- $1 \alpha / \beta$ secretions in nonphagocytic keratinocytes. However, the exact mechanism of nano- $\mathrm{TiO}_{2}$ uptake remains elusive, as blocking lipid raft-mediated, caveolin-dependent, or clathrin-dependent endocytosis did not efficiently block IL-1 $\beta$ secretion [49]. The more knowledge we have of cytokine profiles induced by nanoparticles, the better we can utilize the cytokines as biomarkers of immunomodulatory properties of nanoparticles. Moreover, it is also necessary to clarify whether these proinflammatory cytokines were induced by nanoparticle physiochemical properties or by bacterial endotoxin contaminants.

2.4. Effects of Nanoparticles on Innate Immune Cells. The innate leukocytes include mast cells, neutrophils, eosinophils, basophils, natural killer (NK) cells, gamma/delta T cells, and the phagocytic cells including macrophages and dendritic cells. We summarized several studies which reported the effects of metal-based nanoparticles on phagocytic cells, neutrophils, mast cell, and NK cells. There are still many challenges to investigate the effects and potential applications of nanoparticles to other innate immune cells such as eosinophils, basophils, and gamma/delta T cells.

\subsubsection{Phagocytic Cells (Macrophages, Dendritic Cells).} Macrophages and dendritic cells play many key roles in host defense system. They can remove dead cells and pathogens by phagocytosis. They also can shape the inflammatory response by secreting cytokines through TLR signaling pathway and modulate adaptive immunity by presenting antigens to lymphocytes [58]. In general, macrophages and dendritic cells readily uptake nanoparticles. Therefore, many metal-based nanoparticles (e.g., magnetic nanoparticles and nanoparticles-based PET agents) were commonly used for visualizing of macrophages in human diseases including cancer, atherosclerosis, myocardial infarction, aortic aneurysm, and diabetes [58]. In addition to image applications, targeting tumor-associated macrophages or dendritic cells via nanoparticles for drug, antigen delivery, or vaccine is also a promising tumor therapeutic application. For example, Lin et al. reported that gold nanoparticle delivery of modified $\mathrm{CpG}$ can stimulate macrophages and inhibits tumor growth for immunotherapy [59]. Ahn et al. recently demonstrated that gold nanoparticles enable efficient tumorassociated self-antigen delivery to dendritic cells and then activate the cells to facilitate cross-presentation, inducing antigen-specific cytotoxic $\mathrm{T}$ cell responses for effective cancer therapy [60].

2.4.2. Neutrophils. During acute inflammation, polymorphonuclear neutrophil cells (PMNs) are the first type of leukocytes to migrate to an inflammatory site and then produce several proinflammatory mediators including chemokines, which further attract other PMNs and other cell types like monocytes-macrophages and lymphocytes, corresponding to chronic inflammation. Gold nanoparticles 
were found trapped by neutrophils in their extracellular traps (NETs), being composed mainly of DNA and a variety of antibacterial proteins [61]. The cell-gold networks were visible after as early as $15 \mathrm{~min}$ of treatment of neutrophils with the gold nanoparticles. NETs may contribute to alerting the immune system of a danger signal by activating DNA receptors such as TLR9. This activation might turn out to help in the recruitment of immune cells to mount an acquired immune response or to resolve the inflammation. NETs can either fight inflammatory disease or cause disease depending on the place, time, and dose [62]. However, NETs triggered by nanoparticles need further investigation to figure out their physiological roles. Wang et al. found that delivery of drugs into inflammatory neutrophils by nanoparticles can prevent vascular inflammation [63]. This study provides a novel nanoparticle-based therapeutic approach for targeting activated neutrophils to treat a range of inflammatory disorders.

2.4.3. Mast Cells. Mast cells contain many granules in histamine and heparin and have important roles of allergy and anaphylaxis. When activated, mast cells rapidly release histamine and heparin from their granules to dilate blood vessels and recruit neutrophils and macrophages. Chen et al. demonstrated that $\mathrm{TiO}_{2}$ nanoparticles not only dose-dependently increased histamine secretion, but also increased cytosolic $\mathrm{Ca}^{2+}$ concentration in rat mast cells [93]. Their results suggest that systemic circulation of nanoparticles may prompt histamine release without prior allergen sensitization, causing abnormal inflammatory diseases or potential exacerbating manifestations of multiple allergic responses. It is recently reported that the granules of mast cells are powerful enhancers of adaptive immunity when they are released at sites of infection or vaccine administration. John et al. engineered nanoparticles consisting of mast cells granules to augment immunity during vaccination [94]. It is believed that other metal-based nanoparticles also have possibility of developing this efficient vaccination system.

2.4.4. NK Cells. NK cells control several types of tumors and microbial infections by limiting their spread and subsequent tissue damage. NK cells are also regulatory cells which can interact with dendritic cells, macrophages, $\mathrm{T}$ cells, and endothelial cells. Therefore, NK cells are believed that they can limit or exacerbate immune responses [95]. Clinical study has demonstrated that patients with a high level of NK infiltration were found to have a better prognosis than those with a low level of NK infiltration and suggests that enhancement of NK cell infiltration could be a useful antitumor strategy [96]. Lim et al. provided evidences of cell tracking with quantum dots (QD) by labeling NK cells with anti-CD56 antibody-coated QD705 and tracking the labeled cells up to 12 days after intratumoral injections [97]. The authors further found a decreased size of tumors treated with NK cells compared with controls [97]. QD labeling was thought as the well-suited imaging technique for tracking different cell populations; however, currently available compounds are not clinically applicable because of toxic cadmium cores or other nondegradable components; cadmium-free or biodegradable QDs are currently being developed [98]. Jang et al. used magnetic nanoparticles $\left(\mathrm{Fe}_{3} \mathrm{O}_{4} / \mathrm{SiO}_{2}\right)$ to control movement of human natural killer cells (NK-92MI) by an external magnetic field, loading NK-92MI cells infiltrated into the target tumor site and their killing activity is still maintained the same as the NK-92MI cells without the nanoparticles [99]. This study provides an alternative clinical treatment with reduced toxicity of the nanoparticles and enhanced infiltration of immunology to the three-dimensional target site without surgical treatment.

2.5. Nanoparticles and Adaptive Immunity. Nanoparticles can be designed to deliver vaccine antigens through specific intracellular pathways such as phagocytosis, macropinocytosis, and endocytosis, allowing better antigen presentation for activating the adaptive immune system [100]. Nanoparticles interact most frequently with APCs in the blood circulation, including B cells, macrophages, and dendritic cells. APCs engulf and digest foreign antigens present on the surface major histocompatibility complexes of $\mathrm{B}$ and $\mathrm{T}$ cells [101]. Dendritic cells are the most specialized APCs, which capture and process antigens and migrate to lymphoid tissues leading to $\mathrm{T}$ cell or B cell activation. The costimulatory molecules of dendritic cells and the cytokine environment affect the $\mathrm{T}$ cell response. $\mathrm{T}$ cells including $\mathrm{T}$ helper $(\mathrm{Th})$ cells, regulatory $\mathrm{T}$ cells (formerly known as suppressor T cells), and cytotoxic $\mathrm{T}$ cells express various surface proteins including $\mathrm{CD} 3$ and CD4 on Th cells, CD3, and CD8 on cytotoxic T cells. The cytokine environment is produced by dendritic cells via activated $\mathrm{CD} 4+\mathrm{T}$ cells, neutrophils, and macrophages, which are recruited to the inflammatory site and stromal cells [100]. For example, immature dendritic cell encountered antigens, which are presented to $\mathrm{T}$ cells for self-tolerance ( $\mathrm{T}$ cell anergy) without costimulatory molecule expression. This also occurs for regulatory $\mathrm{T}$ (Treg) cells in the presence of transforming growth factor- $\beta 1$ (TGF- $\beta 1$ ) and interleukin(IL-) 10. Exogenous antigen activates and matures dendritic cells leading to costimulatory molecule expression and Th1, Th2, or Th17 cell activation [102]. Antigen presentation in the IL- 6 and IL-23 cytokine microenvironment can also stimulate naïve CD4+ T cells to differentiate into Th17 cells [100]. Th17 cells are potent inducers of inflammation and play key roles in the development of autoimmunity diseases [103]. Th1 cells mediate cellular immunity and further regulate inflammation responses. On the other hand, Th2 cells induce proliferation of master cells and eosinophils and mediate the differentiation of B cells to produce immunoglobulin (Ig) G and $\mathrm{IgE}$, thereby promoting humoral immunity [42].

2.6. Effects of Nanoparticles on T Cells. Only several metalbased nanoparticles were reported to activate $\mathrm{T}$ cell responses or homeostasis. For example, $\mathrm{TiO}_{2}$ nanoparticles provoke inflammatory cytokines and increase dendritic cell maturation, expression of costimulatory molecules, and prime naïve $\mathrm{T}$ cell activation and proliferation [45]. Cd trapped inside fullerene cage nanoparticles (Gd@C82(OH)22) has specific immunomodulatory effects on $\mathrm{T}$ cells and macrophages, 
including polarization of the cytokine balance towards Th1 cytokines, decreasing the production of Th2 cytokines (IL4, IL-5, and IL-6) and increasing the production of Th1 cytokines (IL-2, IFN- $\gamma$, and TNF- $\alpha$ ) [104]. One important theory of adaptive immunity is $\mathrm{T}$ cell homeostasis (Th1/Th2 balance). Th1 cells drive the cellular immunity to fight viruses and other intracellular pathogens, eliminate cancerous cells, and stimulate delayed-type hypersensitivity skin reactions. Th2 cells drive the humoral immunity and upregulate antibody production to fight extracellular organisms. Overactivation of either pattern can cause disease, and either pathway can downregulate the other [105]. Th1 cells secrete large amounts of interferon- (IFN-) $\gamma$, IL-2, IL3 , granulocyte macrophage colony-stimulating factor, and a small amount of TNF. Th2 cells produce large amounts of IL-3, IL-4, IL-5, IL-6, and IL-10 and a small amount of TNF. Brandenberger et al. demonstrated that silica nanoparticles promote an adjuvant Th2/Th17 response in murine allergic airway disease [106]. Recently, Tomić et al. demonstrated that smaller gold nanoparticles $(10 \mathrm{~nm})$ have stronger inhibitory effects on maturation and antitumor functions of DCs, which were induced either by LPS or heat-killed tumor necrotic cells, compared to larger gold nanoparticles $(50 \mathrm{~nm})$. Gold nanoparticles $(10 \mathrm{~nm})$ can inhibit LPS-induced production of IL-12p70 by dendritic cells and potentiated Th2 polarization, while $50 \mathrm{~nm}$ gold nanoparticles promoted Th17 polarization [107]. The authors supposed that the size-dependent immunomodulatory effects of gold nanoparticles could be attributed to different mechanisms of their internalization, levels of accumulation, and intracellular distribution within DCs, leading to different modulation of maturational signaling. Furthermore, these results point to potential adverse effects of smaller gold nanoparticles if used in photo-thermal therapy and cancer diagnostics. The Th1 or Th2 responses elicited by APCs may be influenced by many factors, such as the maturation states of the APCs and routes of antigen uptake. Nanoparticle size plays a decisive role in determining whether antigens conjugated nanoparticles induce Th1 or Th2 immune responses [108]. Therefore, nanoparticle size may be a critical and fundamental parameter for induction of specific immunity in vaccine development. The precise selection of nanoparticle size for vaccination can influence the type 1/type 2 cytokine balance after one immunization, and this will be useful in the development of effective vaccines against common human pathogens. However, it is still unclear whether other different physical and chemical properties of nanoparticles, such as charge or chemical stability, can drive the $\mathrm{T}$ cell polarization.

2.7. Effects of Nanoparticles on B Cells. B cells are another type of lymphocytes in the adaptive immune system. B cells present unique surface receptor (B cell receptor) to bind with specific antigen. When $B$ cell receptor binds with its specific antigen, antigen is delivered, degraded, and returned to surface bound with MHC class II. This antigen, MHC II complex, can be recognized by antigen-specific $\mathrm{T}$ helper cell. $\mathrm{B}$ cells receive an additional signal from a $\mathrm{T}$ helper cell, further differentiating into antibody-secreting B cells.
It is reported that nanostructure of antigens is used to improve B cell antibody response [109]. Different kinds of synthetic nanoparticles are designed to carry antigens as effective vaccination system [101]. Temchura et al. recently reported that calcium phosphate $(\mathrm{CaP})$ nanoparticles coated with protein antigens are promising vaccine candidates for induction humoral immunity [110]. In general, it is believed that nanoparticles did not result in the activation of Bcells, unless they were coated with the antigen. In contrast, it was also reported that iron oxide nanoparticles can compromise subsequent antigen-specific immune reaction, including antibody productions and $\mathrm{T}$ cell responses [111]. The effects of various metal-based nanoparticles on B cell functions are worthy to further and more comprehensive investigations and further to develop their potential applications.

\subsection{Therapeutic Approach of Nanoparticles on Lymphoma.} Lymphoma is a type of immune cell cancer occurring in B or T lymphocytes which divide faster than normal cells or live longer than they are supposed to. It was reported that the engineering nanoparticles have the potential to develop a nontoxic new treatment for lymphoma and other cancers which does not involve chemotherapy [112]. Yang et al. used gold nanoparticle combined with synthetic HDL (highdensity lipoprotein) to trick B cell lymphoma, which prefers to eat HDL cholesterol. Once the B cell lymphoma cells start eating the gold nanoparticles (or artificial HDL particles), they get plugged up and can no longer feed on any more cholesterol. Deprived of B cell lymphoma's favorite food, the lymphoma cells essentially starve to death. The common treatments of lymphoma are chemotherapy, radiotherapy, or bone marrow transplantation. However, the chemotherapy has strong side effects, even leading to possible long term consequences such as infertility, second cancer risks, and lung damages. Promising and effective nanoparticles drugs may prevent occurrences of these side effects. While designing novel nanodrugs for cancer therapy, we should consider their molecular mechanisms; for example, Ag nanoparticles have been reported to have antiangiogenic ability [113]. Therefore, Ag nanoparticles are one of attractive and potential approaches to develop antitumor effect. Sriram et al. also demonstrated the antitumor activity of silver nanoparticles in Dalton's lymphoma ascites tumor model both in vitro and in vivo by activation of caspase-3 enzyme [114]. Moreover, nanodrugs are mainly developed according to their ability to distinguish between malignant and nonmalignant cells, making them a promising alternative to existing drugs. The targeting efficiency of nanoparticles can be accomplished by combining with RGD peptide [115] or antibody against specific tumor markers [116]. In a nutshell, nanoparticles may provide a new way to kill lymphoma without chemotherapy.

\section{Conclusion and Future Perspectives}

Nanoparticles can be used as vaccine carriers, adjuvants, and drug delivery vehicles to target specific inflammationassociated diseases or cancer. Nanoparticles, particularly 
noble metal nanoparticles, have considerable potential for biomedical applications, such as diagnostic assays, thermal ablation, and radiotherapy enhancement as well as drug and gene delivery. Currently, we are still challenged by limited knowledge of nanoparticle pharmacokinetics, biodistribution, and immunotoxicity.

The interactions of nanomaterials with the immune system have attracted increasing attention. The physicochemical properties of nanoparticles influence the immunological effects of nanoparticles. Comprehensive studies to explore the effects of physicochemical properties (such as size, shape, and charge) on the immunotoxicity of metal-based nanoparticles are still needed. Assessment of potential adverse effects on the immune system is also a critical component of the overall evaluation of nanodrug toxicity. Further mechanistic studies investigating nanoparticle immunomodulatory effects or inflammatory reactions are required to improve knowledge of the physicochemical properties of nanoparticles, which influences the immune system. A cooperation between materials science and immunology, immunobioengineering, is an emerging field which has great potential to develop prophylactic and therapeutic vaccine applicants.

\section{Disclosure}

All authors are aware of and agree to the content of the paper and their being listed as an author of the paper.

\section{Conflict of Interests}

The authors declare no competing financial interests.

\section{Acknowledgment}

This work was supported by research Grants NM-103-PP-08 and BN-104-PP-28 from the Institute of Biomedical Engineering and Nanomedicine at the National Health Research Institutes, Taiwan.

\section{References}

[1] P. S. Tourinho, C. A. M. van Gestel, S. Lofts, C. Svendsen, A. M. V. M. Soares, and S. Loureiro, "Metal-based nanoparticles in soil: fate, behavior, and effects on soil invertebrates," Environmental Toxicology and Chemistry, vol. 31, no. 8, pp. 1679-1692, 2012.

[2] L. Mu and R. L. Sprando, "Application of nanotechnology in cosmetics," Pharmaceutical Research, vol. 27, no. 8, pp. 17461749, 2010.

[3] M. D. Newman, M. Stotland, and J. I. Ellis, "The safety of nanosized particles in titanium dioxide- and zinc oxide-based sunscreens," Journal of the American Academy of Dermatology, vol. 61, no. 4, pp. 685-692, 2009.

[4] N. Durán, P. D. Marcato, G. I. H. de Souza, O. L. Alves, and E. Esposito, "Antibacterial effect of silver nanoparticles produced by fungal process on textile fabrics and their effluent treatment," Journal of Biomedical Nanotechnology, vol. 3, no. 2, pp. 203-208, 2007.
[5] T. M. Benn and P. Westerhoff, "Nanoparticle silver released into water from commercially available sock fabrics," Environmental Science \& Technology, vol. 42, no. 11, pp. 4133-4139, 2008.

[6] A. Panáček, L. Kvítek, R. Prucek et al., "Silver colloid nanoparticles: synthesis, characterization, and their antibacterial activity," The Journal of Physical Chemistry B, vol. 110, no. 33, pp. 1624816253, 2006.

[7] C. Baker, A. Pradhan, L. Pakstis, D. J. Pochan, and S. I. Shah, "Synthesis and antibacterial properties of silver nanoparticles," Journal of Nanoscience and Nanotechnology, vol. 5, no. 2, pp. 244-249, 2005.

[8] R. Kaegi, B. Sinnet, S. Zuleeg et al., "Release of silver nanoparticles from outdoor facades," Environmental Pollution, vol. 158, no. 9, pp. 2900-2905, 2010.

[9] F. Zhang, X. L. Wu, Y. Y. Chen, and H. Lin, "Application of silver nanoparticles to cotton fabric as an antibacterial textile finish," Fibers and Polymers, vol. 10, no. 4, pp. 496-501, 2009.

[10] A. M. Schrand, M. F. Rahman, S. M. Hussain, J. J. Schlager, D. A. Smith, and A. F. Syed, "Metal-based nanoparticles and their toxicity assessment," Wiley Interdisciplinary Reviews: Nanomedicine and Nanobiotechnology, vol. 2, no. 5, pp. 544-568, 2010.

[11] K. L. Dreher, "Health and environmental impact of nanotechnology: toxicological assessment of manufactured nanoparticles," Toxicological Sciences, vol. 77, no. 1, pp. 3-5, 2004.

[12] G. Oberdörster, A. Maynard, K. Donaldson et al., "Principles for characterizing the potential human health effects from exposure to nanomaterials: elements of a screening strategy," Particle and Fibre Toxicology, vol. 2, article 8, 2005.

[13] A. Nel, T. Xia, L. Mädler, and N. Li, “Toxic potential of materials at the nanolevel," Science, vol. 311, no. 5761, pp. 622-627, 2006.

[14] A. E. Nel, L. Mädler, D. Velegol et al., "Understanding biophysicochemical interactions at the nano-bio interface," Nature Materials, vol. 8, no. 7, pp. 543-557, 2009.

[15] K. Tiede, A. B. A. Boxall, S. P. Tear, J. Lewis, H. David, and M. Hassellov, "Detection and characterization of engineered nanoparticles in food and the environment," Food Additives and Contaminants, Part A: Chemistry, Analysis, Control, Exposure \& Risk Assessment, vol. 25, no. 7, pp. 795-821, 2008.

[16] T. H. Mogensen, "Pathogen recognition and inflammatory signaling in innate immune defenses," Clinical Microbiology Reviews, vol. 22, no. 2, pp. 240-273, 2009.

[17] D. F. Moyano, M. Goldsmith, D. J. Solfiell et al., "Nanoparticle hydrophobicity dictates immune response," Journal of the American Chemical Society, vol. 134, no. 9, pp. 3965-3967, 2012.

[18] D. Boraschi, L. Costantino, and P. Italiani, "Interaction of nanoparticles with immunocompetent cells: nanosafety considerations," Nanomedicine (London), vol. 7, no. 1, pp. 121-131, 2012.

[19] B. S. Zolnik, Á. González-Fernández, N. Sadrieh, and M. A. Dobrovolskaia, "Nanoparticles and the immune system," Endocrinology, vol. 151, no. 2, pp. 458-465, 2010.

[20] M. A. Dobrovolskaia and S. E. McNeil, "Immunological properties of engineered nanomaterials," Nature Nanotechnology, vol. 2, no. 8, pp. 469-478, 2007.

[21] S. M. Moghimi, "Chemical camouflage of nanospheres with a poorly reactive surface: towards development of stealth and target-specific nanocarriers," Biochimica et Biophysica Acta, vol. 1590, no. 1-3, pp. 131-139, 2002.

[22] X. Wang, T. Ishida, and H. Kiwada, "Anti-PEG IgM elicited by injection of liposomes is involved in the enhanced blood clearance of a subsequent dose of PEGylated liposomes," Journal of Controlled Release, vol. 119, no. 2, pp. 236-244, 2007. 
[23] T. Ishida, X. Wang, T. Shimizu, K. Nawata, and H. Kiwada, "PEGylated liposomes elicit an anti-PEG IgM response in a T cell-independent manner," Journal of Controlled Release, vol. 122, no. 3, pp. 349-355, 2007.

[24] A. L. Engel, G. E. Holt, and H. Lu, "The pharmacokinetics of Toll-like receptor agonists and the impact on the immune system," Expert Review of Clinical Pharmacology, vol. 4, no. 2, pp. 275-289, 2011.

[25] K. Takeda and S. Akira, “TLR signaling pathways," Seminars in Immunology, vol. 16, no. 1, pp. 3-9, 2004.

[26] R. Medzhitov, P. Preston-Hurlburt, and C. A. Janeway Jr., "A human homologue of the Drosophila Toll protein signals activation of adaptive immunity," Nature, vol. 388, no. 6640, pp. 394-397, 1997.

[27] A. Makkouk and A. M. Abdelnoor, "The potential use of Toll-like receptor (TLR) agonists and antagonists as prophylactic and/or therapeutic agents," Immunopharmacology and Immunotoxicology, vol. 31, no. 3, pp. 331-338, 2009.

[28] I. Tamayo, J. M. Irache, C. Mansilla, J. Ochoa-Repáraz, J. J. Lasarte, and C. Gamazo, "Poly(anhydride) nanoparticles act as active Thl adjuvants through Toll-like receptor exploitation," Clinical and Vaccine Immunology, vol. 17, no. 9, pp. 1356-1362, 2010.

[29] S. Gnjatic, N. B. Sawhney, and N. Bhardwaj, "Toll-like receptor agonists are they good adjuvants?" Cancer Journal, vol. 16, no. 4, pp. 382-391, 2010.

[30] K. Tse and A. A. Horner, "Update on Toll-like receptor-directed therapies for human disease," Annals of the Rheumatic Diseases, vol. 66, supplement 3, pp. iii77-iii80, 2007.

[31] T. Kawai and S. Akira, "The role of pattern-recognition receptors in innate immunity: update on Toll-like receptors," Nature Immunology, vol. 11, no. 5, pp. 373-384, 2010.

[32] E. I. Lafferty, S. T. Qureshi, and M. Schnare, "The role of Tolllike receptors in acute and chronic lung inflammation," Journal of Inflammation (London), vol. 7, article 57, 2010.

[33] T. Kawai and S. Akira, "Toll-like receptor and RIG-1-like receptor signaling," Annals of the New York Academy of Sciences, vol. 1143, pp. 1-20, 2008.

[34] M. Schmidt, B. Raghavan, V. Müller et al., "Crucial role for human Toll-like receptor 4 in the development of contact allergy to nickel," Nature Immunology, vol. 11, no. 9, pp. 814-819, 2010.

[35] D. M. Smith, J. K. Simon, and J. R. Baker Jr., "Applications of nanotechnology for immunology," Nature Reviews Immunology, vol. 13, no. 8, pp. 592-605, 2013.

[36] M. Lucarelli, A. M. Gatti, G. Savarino et al., "Innate defence functions of macrophages can be biased by nano-sized ceramic and metallic particles," European Cytokine Network, vol. 15, no. 4, pp. 339-346, 2004.

[37] Y. L. Cui, H. T. Liu, M. Zhou et al., "Signaling pathway of inflammatory responses in the mouse liver caused by $\mathrm{TiO}_{2}$ nanoparticles," Journal of Biomedical Materials Research Part A, vol. 96, no. 1, pp. 221-229, 2011.

[38] P. M. Castillo, J. L. Herrera, R. Fernandez-Montesinos et al., "Tiopronin monolayer-protected silver nanoparticles modulate IL-6 secretion mediated by Toll-like receptor ligands," Nanomedicine (London), vol. 3, no. 5, pp. 627-635, 2008.

[39] H. Chang, C.-C. Ho, C. S. Yang et al., "Involvement of MyD88 in zinc oxide nanoparticle-induced lung inflammation," Experimental and Toxicologic Pathology, vol. 65, no. 6, pp. 887-896, 2013.
[40] C.-C. Ho, Y.-H. Luo, T.-H. Chuang, C.-S. Yang, Y.-C. Ling, and P. Lin, "Quantum dots induced monocyte chemotactic protein1 expression via MyD88-dependent Toll-like receptor signaling pathways in macrophages," Toxicology, vol. 308, pp. 1-9, 2013.

[41] P. Chen, K. Kanehira, and A. Taniguchi, "Role of Toll-like receptors 3, 4 and 7 in cellular uptake and response to titanium dioxide nanoparticles," Science and Technology of Advanced Materials, vol. 14, no. 1, Article ID 015008, 2013.

[42] M. Elsabahy and K. L. Wooley, "Cytokines as biomarkers of nanoparticle immunotoxicity," Chemical Society Reviews, vol. 42, no. 12, pp. 5552-5576, 2013.

[43] W. Kozak, M. J. Kluger, D. Soszynski et al., "IL-6 and IL-1beta in fever-studies using cytokine-deficient (knockout) mice," Annals of the New York Academy of Sciences, vol. 856, pp. 3347, 1998.

[44] S. Struyf, M. Gouwy, C. Dillen, P. Proost, G. Opdenakker, and J. van Damme, "Chemokines synergize in the recruitment of circulating neutrophils into inflamed tissue," European Journal of Immunology, vol. 35, no. 5, pp. 1583-1591, 2005.

[45] B. C. Schanen, A. S. Karakoti, S. Seal, D. R. Drake III, W. L. Warren, and W. T. Self, "Exposure to titanium dioxide nanomaterials provokes inflammation of an in vitro human immune construct," ACS Nano, vol. 3, no. 9, pp. 2523-2532, 2009.

[46] M. Ghoneum, A. Ghoneum, and J. Gimzewski, "Nanodiamond and nanoplatinum liquid, DPV576, activates human monocytederived dendritic cells in vitro," Anticancer Research, vol. 30, no. 10, pp. 4075-4079, 2010.

[47] C. Hanley, A. Thurber, C. Hanna, A. Punnoose, J. Zhang, and D. G. Wingett, "The influences of cell Type and $\mathrm{ZnO}$ nanoparticle size on immune cell cytotoxicity and cytokine induction," Nanoscale Research Letters, vol. 4, no. 12, pp. 1409$1420,2009$.

[48] H. A. Khan, M. A. K. Abdelhalim, A. S. Alhomida, and M. S. Al Ayed, "Transient increase in IL-1beta, IL-6 and TNF-alpha gene expression in rat liver exposed to gold nanoparticles," Genetics and Molecular Research, vol. 12, no. 4, pp. 5851-5857, 2013.

[49] A. S. Yazdi, G. Guarda, N. Riteau et al., "Nanoparticles activate the NLR pyrin domain containing 3 (Nlrp3) inflammasome and cause pulmonary inflammation through release of IL- $1 \alpha$ and IL$1 \beta$," Proceedings of the National Academy of Sciences of the United States of America, vol. 107, no. 45, pp. 19449-19454, 2010.

[50] V. Pétrilli, S. Papin, C. Dostert, A. Mayor, F. Martinon, and J. Tschopp, "Activation of the NALP3 inflammasome is triggered by low intracellular potassium concentration," Cell Death and Differentiation, vol. 14, no. 9, pp. 1583-1589, 2007.

[51] S. L. Demento, S. C. Eisenbarth, H. G. Foellmer et al., "Inflammasome-activating nanoparticles as modular systems for optimizing vaccine efficacy," Vaccine, vol. 27, no. 23, pp. 3013-3021, 2009.

[52] A. C. Reisetter, L. V. Stebounova, J. Baltrusaitis et al., "Induction of inflammasome-dependent pyroptosis by carbon black nanoparticles," The Journal of Biological Chemistry, vol. 286, no. 24, pp. 21844-21852, 2011.

[53] E.-J. Yang, S. Kim, J. S. Kim, and I.-H. Choi, "Inflammasome formation and IL-1beta release by human blood monocytes in response to silver nanoparticles," Biomaterials, vol. 33, no. 28, pp. 6858-6867, 2012.

[54] M. Yang, K. Flavin, I. Kopf et al., "Functionalization of carbon nanoparticles modulates inflammatory cell recruitment and NLRP3 inflammasome activation," Small, vol. 9, no. 24, pp. 4194-4206, 2013. 
[55] P. M. Peeters, T. N. Perkins, E. F. M. Wouters, B. T. Mossman, and N. L. Reynaert, "Silica induces NLRP3 inflammasome activation in human lung epithelial cells," Particle and Fibre Toxicology, vol. 10, no. 1, article 3, 2013.

[56] V. Hornung, F. Bauernfeind, A. Halle et al., "Silica crystals and aluminum salts activate the NALP3 inflammasome through phagosomal destabilization," Nature Immunology, vol. 9, no. 8, pp. 847-856, 2008.

[57] F. A. Sharp, D. Ruane, B. Claass et al., "Uptake of particulate vaccine adjuvants by dendritic cells activates the NALP 3 inflammasome," Proceedings of the National Academy of Sciences of the United States of America, vol. 106, no. 3, pp. 870-875, 2009.

[58] R. Weissleder, M. Nahrendorf, and M. J. Pittet, "Imaging macrophages with nanoparticles," Nature Materials, vol. 13, no. 2, pp. 125-138, 2014.

[59] A. Y. Lin, J. P. M. Almeida, A. Bear et al., "Gold nanoparticle delivery of modified $\mathrm{CpG}$ stimulates macrophages and inhibits tumor growth for enhanced immunotherapy," PLOS ONE, vol. 8, no. 5, Article ID e63550, 2013.

[60] S. Ahn, I.-H. Lee, S. Kang et al., "Gold nanoparticles displaying tumor-associated self-antigens as a potential vaccine for cancer immunotherapy," Advanced Healthcare Materials, vol. 3, no. 8, pp. 1194-1199, 2014.

[61] M. Bartneck, H. A. Keul, G. Zwadlo-Klarwasser, and J. Groll, "Phagocytosis independent extracellular nanoparticle clearance by human immune cells," Nano Letters, vol. 10, no. 1, pp. 59-63, 2010.

[62] V. Brinkmann and A. Zychlinsky, "Neutrophil extracellular traps: is immunity the second function of chromatin?" Journal of Cell Biology, vol. 198, no. 5, pp. 773-783, 2012.

[63] Z. J. Wang, J. Li, J. Cho, and A. B. Malik, "Prevention of vascular inflammation by nanoparticle targeting of adherent neutrophils," Nature Nanotechnology, vol. 9, no. 3, pp. 204-210, 2014.

[64] S. Lanone, F. Rogerieux, J. Geys et al., "Comparative toxicity of 24 manufactured nanoparticles in human alveolar epithelial and macrophage cell lines," Particle and Fibre Toxicology, vol. 6, article 14, 2009.

[65] S. George, S. Pokhrel, T. Xia et al., "Use of a rapid cytotoxicity screening approach to engineer a safer zinc oxide nanoparticle through iron doping," ACS Nano, vol. 4, no. 1, pp. 15-29, 2010.

[66] T. Xia, M. Kovochich, M. Liong et al., "Comparison of the mechanism of toxicity of zinc oxide and cerium oxide nanoparticles based on dissolution and oxidative stress properties," ACS Nano, vol. 2, no. 10, pp. 2121-2134, 2008.

[67] T. J. Brunner, P. Wick, P. Manser et al., "In vitro cytotoxicity of oxide nanoparticles: comparison to asbestos, silica, and the effect of particle solubility," Environmental Science \& Technology, vol. 40, no. 14, pp. 4374-4381, 2006.

[68] C. M. Sayes, K. L. Reed, and D. B. Warheit, "Assessing toxicity of fine and nanoparticles: comparing in vitro measurements to in vivo pulmonary toxicity profiles," Toxicological Sciences, vol. 97, no. 1, pp. 163-180, 2007.

[69] H. A. Jeng and J. Swanson, "Toxicity of metal oxide nanoparticles in mammalian cells," Journal of Environmental Science and Health Part A: Toxic/Hazardous Substances \& Environmental Engineering, vol. 41, no. 12, pp. 2699-2711, 2006.

[70] M. R. Riley, D. E. Boesewetter, R. A. Turner et al., "Comparison of the sensitivity of three lung derived cell lines to metals from combustion derived particulate matter," Toxicology in Vitro, vol. 19, no. 3, pp. 411-419, 2005.
[71] K. F. Soto, A. Carrasco, T. G. Powell et al., "Comparative in vitro cytotoxicity assessment of some manufactured nanoparticulate materials characterized by transmission electron microscopy," Journal of Nanoparticle Research, vol. 7, no. 2-3, pp. 145-169, 2005.

[72] K. Soto, K. M. Garza, and L. E. Murr, "Cytotoxic effects of aggregated nanomaterials," Acta Biomaterialia, vol. 3, no. 3, pp. 351-358, 2007.

[73] S. M. Hussain, K. L. Hess, J. M. Gearhart et al., "In vitro toxicity of nanoparticles in BRL 3A rat liver cells," Toxicology in Vitro, vol. 19, no. 7, pp. 975-983, 2005.

[74] S. M. Hussain, A. K. Javorina, A. M. Schrand et al., "The interaction of manganese nanoparticles with PC-12 cells induces dopamine depletion," Toxicological Sciences, vol. 92, no. 2, pp. 456-463, 2006.

[75] K. F. Soto, A. Carrasco, T. G. Powell et al., "Biological effects of nanoparticulate materials," Materials Science \& Engineering C: Biomimetic and Supramolecular Systems, vol. 26, no. 8, pp. 14211427, 2006.

[76] L. Braydich-Stolle, S. Hussain, J. J. Schlager, and M. C. Hofmann, "In vitro cytotoxicity of nanoparticles in mammalian germline stem cells," Toxicological Sciences, vol. 88, no. 2, pp. 412-419, 2005.

[77] J. Y. Wang, M. F. Rahman, H. M. Duhart et al., "Expression changes of dopaminergic system-related genes in PC12 cells induced by manganese, silver, or copper nanoparticles," Neurotoxicology, vol. 30, no. 6, pp. 926-933, 2009.

[78] J. M. Veranth, E. G. Kaser, M. M. Veranth et al., "Cytokine responses of human lung cells (BEAS-2B) treated with micronsized and nanoparticles of metal oxides compared to soil dusts," Particle and Fibre Toxicology, vol. 4, article 2, 2007.

[79] L. K. Limbach, P. Wick, P. Manser et al., "Exposure of engineered nanoparticles to human lung epithelial cells: influence of chemical composition and catalytic activity on oxidative stress," Environmental Science \& Technology, vol. 41, no. 11, pp. 41584163, 2007.

[80] A. J. Wagner, C. A. Bleckmann, R. C. Murdock et al., "Cellular interaction of different forms of aluminum nanoparticles in rat alveolar macrophages," The Journal of Physical Chemistry B, vol. 111, no. 25, pp. 7353-7359, 2007.

[81] Y. S. Kim, J. S. Kim, H. S. Cho et al., "Twenty-eight-day oral toxicity, genotoxicity, and gender-related tissue distribution of silver nanoparticles in Sprague-Dawley rats," Inhalation Toxicology, vol. 20, no. 6, pp. 575-583, 2008.

[82] J. H. Ji, J. H. Jung, S. S. Kim et al., "Twenty-eight-day inhalation toxicity study of silver nanoparticles in Sprague-Dawley rats," Inhalation Toxicology, vol. 19, no. 10, pp. 857-871, 2007.

[83] P. V. Asharani, Y. L. Wu, Z. Y. Gong, and S. Valiyaveettil, “Toxicity of silver nanoparticles in zebrafish models," Nanotechnology, vol. 19, no. 25, Article ID 255102, 2008.

[84] J. P. Chen, S. Patil, S. Seal, and J. F. McGinnis, "Rare earth nanoparticles prevent retinal degeneration induced by intracellular peroxides," Nature Nanotechnology, vol. 1, no. 2, pp. 142150, 2006.

[85] M. F. Rahman, J. Wang, T. A. Patterson et al., "Expression of genes related to oxidative stress in the mouse brain after exposure to silver-25 nanoparticles," Toxicology Letters, vol. 187, no. 1, pp. 15-21, 2009.

[86] H. S. Sharma, "Hyperthermia induced brain oedema: current status \& future perspectives," Indian Journal of Medical Research, vol. 123, no. 5, pp. 629-652, 2006. 
[87] J. F. Hillyer and R. M. Albrecht, "Gastrointestinal persorption and tissue distribution of differently sized colloidal gold nanoparticles," Journal of Pharmaceutical Sciences, vol. 90, no. 12, pp. 1927-1936, 2001.

[88] R. J. Griffitt, R. Weil, K. A. Hyndman et al., "Exposure to copper nanoparticles causes gill injury and acute lethality in zebrafish (Danio rerio)," Environmental Science \& Technology, vol. 41, no. 23, pp. 8178-8186, 2007.

[89] Z. Chen, H. A. Meng, G. M. Xing et al., "Acute toxicological effects of copper nanoparticles in vivo," Toxicology Letters, vol. 163, no. 2, pp. 109-120, 2006.

[90] M. T. Zhu, W. Y. Feng, B. Wang et al., "Comparative study of pulmonary responses to nano- and submicron-sized ferric oxide in rats," Toxicology, vol. 247, no. 2-3, pp. 102-111, 2008.

[91] J. X. Wang, G. Q. Zhou, C. Y. Chen et al., "Acute toxicity and biodistribution of different sized titanium dioxide particles in mice after oral administration," Toxicology Letters, vol. 168, no. 2, pp. 176-185, 2007.

[92] J. S. Kim, T. J. Yoon, B. G. Kim et al., "Toxicity and tissue distribution of magnetic nanoparticles in mice," Toxicological Sciences, vol. 89, no. 1, pp. 338-347, 2006.

[93] E. Y. Chen, M. Garnica, Y.-C. Wang, A. J. Mintz, C.-S. Chen, and W.-C. Chin, "A mixture of anatase and rutile $\mathrm{TiO}_{2}$ nanoparticles induces histamine secretion in mast cells," Particle and Fibre Toxicology, vol. 9, article 2, 2012.

[94] A. L. S. John, C. Y. Chan, H. F. Staats, K. W. Leong, and S. N. Abraham, "Synthetic mast-cell granules as adjuvants to promote and polarize immunity in lymph nodes," Nature Materials, vol. 11, no. 3, pp. 250-257, 2012.

[95] E. Vivier, E. Tomasello, M. Baratin, T. Walzer, and S. Ugolini, "Functions of natural killer cells," Nature Immunology, vol. 9, no. 5, pp. 503-510, 2008.

[96] S. Ishigami, S. Natsugoe, K. Tokuda et al., "Prognostic value of intratumoral natural killer cells in gastric carcinoma," Cancer, vol. 88 , no. 3, pp. 577-583, 2000.

[97] Y. T. Lim, M. Y. Cho, Y.-W. Noh, J. W. Chung, and B. H. Chung, "Near-infrared emitting fluorescent nanocrystals-labeled natural killer cells as a platform technology for the optical imaging of immunotherapeutic cells-based cancer therapy," Nanotechnology, vol. 20, no. 47, Article ID 475102, 2009.

[98] P. Jha, D. Golovko, S. Bains et al., "Monitoring of natural killer cell immunotherapy using noninvasive imaging modalities," Cancer Research, vol. 70, no. 15, pp. 6109-6113, 2010.

[99] E.-S. Jang, J.-H. Shin, G. Ren et al., "The manipulation of natural killer cells to target tumor sites using magnetic nanoparticles," Biomaterials, vol. 33, no. 22, pp. 5584-5592, 2012.

[100] J. A. Hubbell, S. N. Thomas, and M. A. Swartz, "Materials engineering for immunomodulation," Nature, vol. 462, no. 7272, pp. 449-460, 2009.

[101] A. E. Gregory, R. Titball, and D. Williamson, "Vaccine delivery using nanoparticles," Frontiers in Cellular and Infection Microbiology, vol. 3, article 13, 2013.

[102] N. A. Capurso, M. Look, L. Jeanbart et al., "Development of a nanoparticulate formulation of retinoic acid that suppresses Th17 cells and upregulates regulatory T cells," Self/NonselfImmune Recognition and Signaling, vol. 1, no. 4, pp. 335-340, 2010.

[103] E. Bettelli, M. Oukka, and V. K. Kuchroo, "T(H)-17 cells in the circle of immunity and autoimmunity," Nature Immunology, vol. 8, no. 4, pp. 345-350, 2007.
[104] Y. Liu, F. Jiao, Y. Qiu et al., "The effect of $\mathrm{Gd} @ \mathrm{C}_{82}(\mathrm{OH})_{22}$ nanoparticles on the release of Th1/Th2 cytokines and induction of TNF- $\alpha$ mediated cellular immunity," Biomaterials, vol. 30, no. 23-24, pp. 3934-3945, 2009.

[105] P. Kidd, "Th1/Th2 balance: the hypothesis, its limitations, and implications for health and disease," Alternative Medicine Review, vol. 8, no. 3, pp. 223-246, 2003.

[106] C. Brandenberger, N. L. Rowley, D. N. Jackson-Humbles et al., "Engineered silica nanoparticles act as adjuvants to enhance allergic airway disease in mice," Particle and Fibre Toxicology, vol. 10, no. 1, article 26, 2013.

[107] S. Tomić, J. Đokić, S. Vasilijić et al., "Size-dependent effects of gold nanoparticles uptake on maturation and antitumor functions of human dendritic cells in vitro," PLOS ONE, vol. 9, no. 5, Article ID e96584, 2014.

[108] P. L. Mottram, D. Leong, B. Crimeen-Irwin et al., “Type 1 and 2 immunity following vaccination is influenced by nanoparticle size: formulation of a model vaccine for respiratory syncytial virus," Molecular Pharmaceutics, vol. 4, no. 1, pp. 73-84, 2007.

[109] T. Storni, T. M. Kündig, G. Senti, and P. Johansen, "Immunity in response to particulate antigen-delivery systems," Advanced Drug Delivery Reviews, vol. 57, no. 3, pp. 333-355, 2005.

[110] V. V. Temchura, D. Kozlova, V. Sokolova, K. Überla, and M. Epple, "Targeting and activation of antigen-specific B-cells by calcium phosphate nanoparticles loaded with protein antigen," Biomaterials, vol. 35, no. 23, pp. 6098-6105, 2014.

[111] C.-C. Shen, C.-C. Wang, M.-H. Liao, and T.-R. Jan, "A single exposure to iron oxide nanoparticles attenuates antigen-specific antibody production and T-cell reactivity in ovalbumin-sensitized BALB/c mice," International Journal of Nanomedicine, vol. 6, pp. 1229-1235, 2011.

[112] S. Yang, M. G. Damiano, H. Zhang et al., "Biomimetic, synthetic HDL nanostructures for lymphoma," Proceedings of the National Academy of Sciences of the United States of America, vol. 110, no. 7, pp. 2511-2516, 2013.

[113] S. Gurunathan, K. J. Lee, K. Kalishwaralal, S. Sheikpranbabu, R. Vaidyanathan, and S. H. Eom, "Antiangiogenic properties of silver nanoparticles," Biomaterials, vol. 30, no. 31, pp. 6341-6350, 2009.

[114] M. I. Sriram, S. B. M. Kanth, K. Kalishwaralal, and S. Gurunathan, "Antitumor activity of silver nanoparticles in Dalton's lymphoma ascites tumor model," International Journal of Nanomedicine, vol. 5, no. 1, pp. 753-762, 2010.

[115] E. Garanger, D. Boturyn, and P. Dumy, "Tumor targeting with RGD peptide ligands-design of new molecular conjugates for imaging and therapy of cancers," Anti-Cancer Agents in Medicinal Chemistry, vol. 7, no. 5, pp. 552-558, 2007.

[116] A. M. Scott, J. P. Allison, and J. D. Wolchok, "Monoclonal antibodies in cancer therapy," Cancer Immunity, vol. 12, article $14,2012$. 

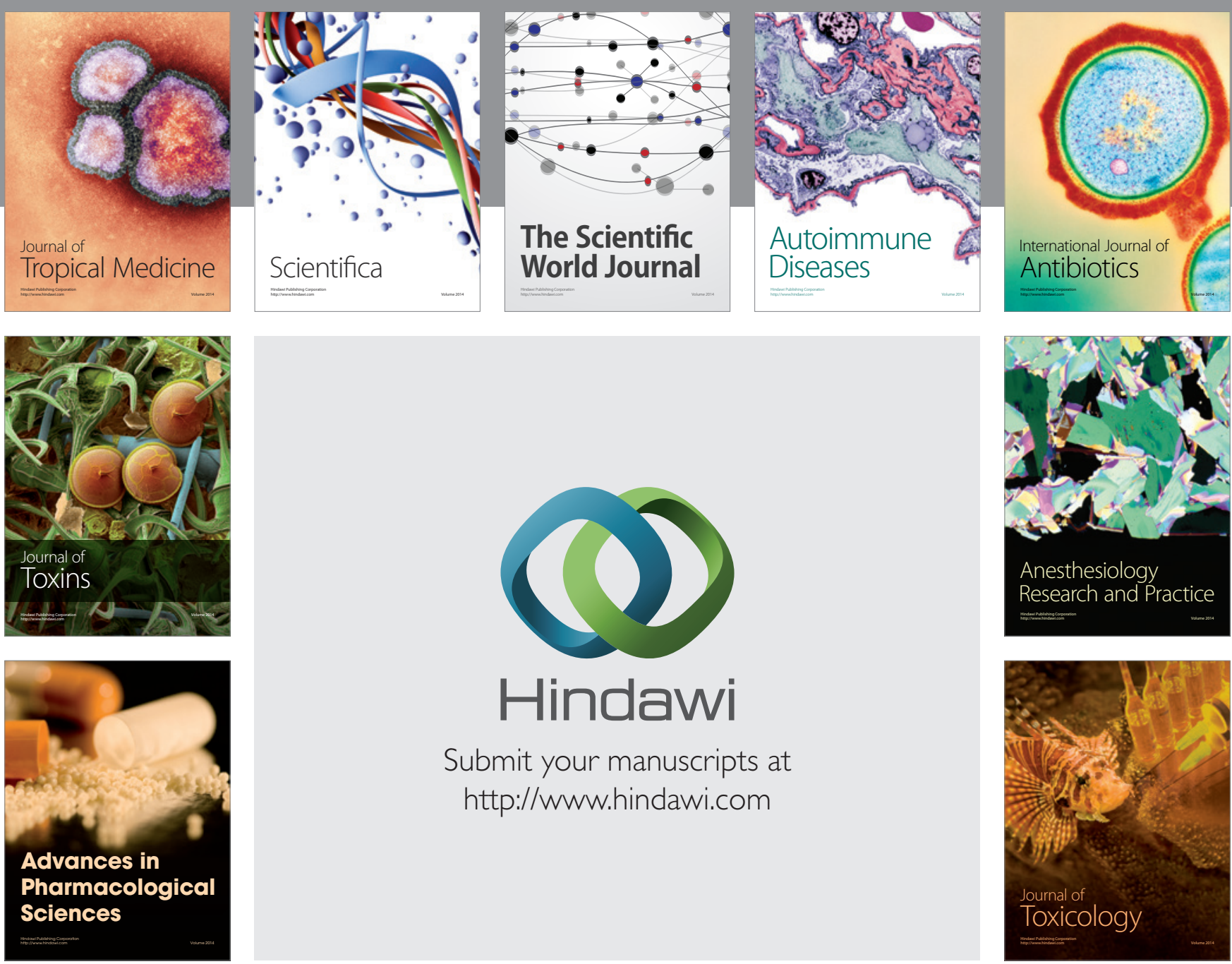

\section{Hindawi}

Submit your manuscripts at

http://www.hindawi.com
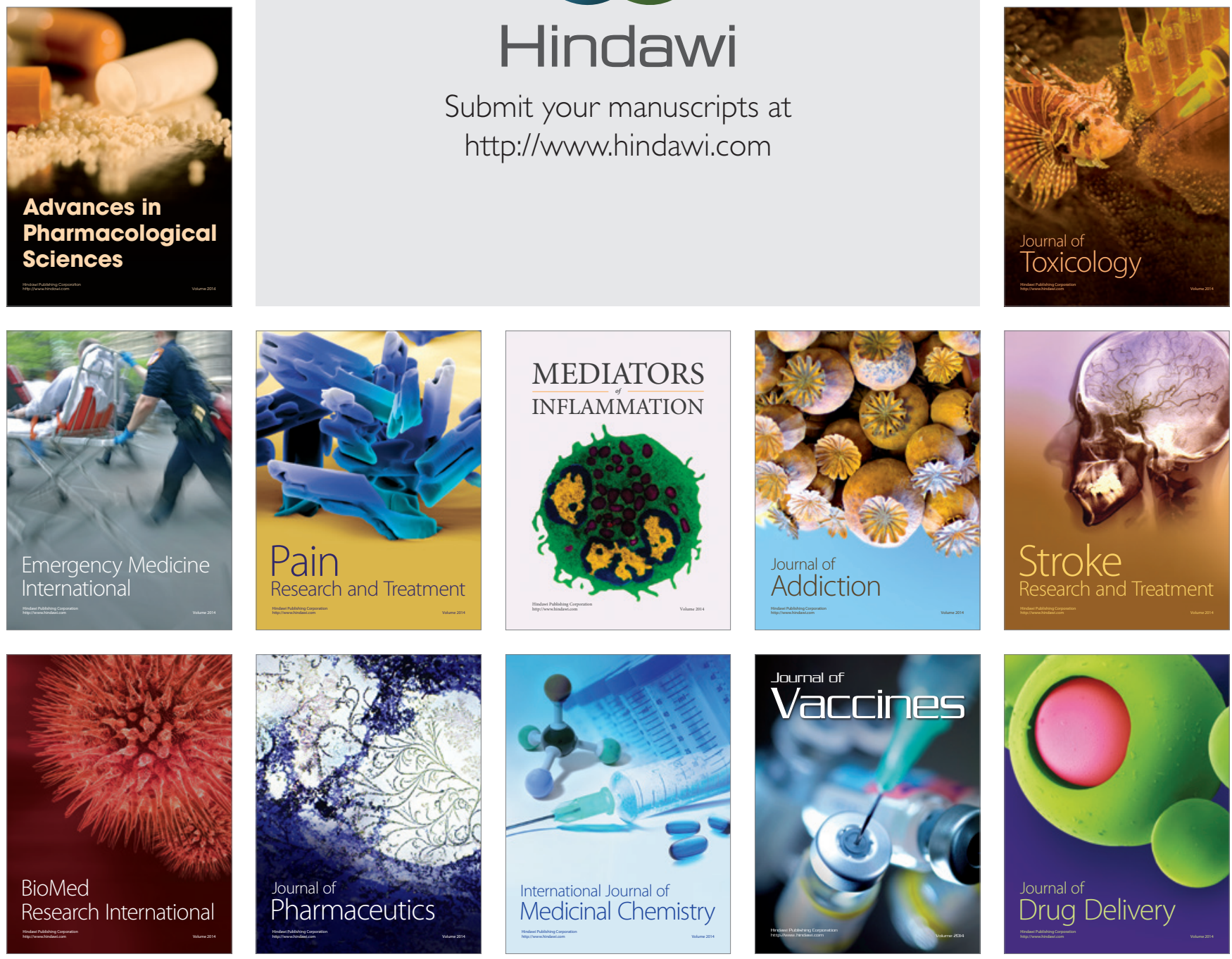